\title{
Tıp Fakültesi Öğrencilerinin Sanal Zorba ve Sanal Kurban Olma Durumlarının İncelenmesi
}

\section{Investigation of Being a Cyberbully and a Cybervictim among the Medical Students}

Barış SEZER* (ORCID: 0000-0003-0695-0819)

Meral DEMIRÖREN* (ORCID: 0000-0001-7415-9602)

*Hacettepe Üniversitesi Tıp Fakültesi Ankara, TÜRKIYE

Sorumlu Yazar: Barış SEZER, E-Posta: barissezer13@hotmail.com

\section{Özet}

Amaç: Teknolojnin gelişimi üniversite öğrencileri arasında etkileşimi artırması, öğrenmenin desteklenmesi gibi katkılarının yanında, bazı olumsuz durumları da beraberinde getirmektedir. $\mathrm{Bu}$ durumlardan biri de sanal zorbalık (cyberbullying) kavramıdır. Bu çalışmada fakültelerinde birinci sınıfta öğrenim gören Hacettepe Üniversitesi Tıp Fakültesi öğrencilerinin sanal zorba/kurban olma durumlarının belirlenmesi amaçlanmıştır.

Yöntem: Araştırma tarama modeline göre gerçekleştirilmiştir. Çalışma grubu 307 öğrenciden (tüm öğrenci sayısının \%74'ü) oluşmuştur. Veriler; Kişisel Bilgi Formu ve Sanal Zorba/Kurban Ölçeği ile elektronik yoldan toplanmıştır. Verilerin analizi SPSS 22.0 istatistik paket programı ile yapılmıştır. Tanımlayıcı istatistikler sayı, yüzde, ortalama ve standart sapma olarak sunulmuştur. Verilerin analizi için

Anahtar sözcükler:

Sanal Zorbalık, Sanal

Kurban, Sanal Zorbalık

Farkındalığ 1

Keywords:

Cyberbullying,

Cybervictim,

Cyberbullying

Awareness

Gönderilme Tarihi

Submitted: 24.03 .2021

Kabul Tarihi

Accepted: 19.05.2021 parametrik olmayan testlerden Mann Whitney U ve Kruskal Wallis testleri kullanılmıștır.

Bulgular: Öğrencilerin sanal zorba $(\bar{X}=21,04 \pm 3,64)$ ve sanal kurban ( $\bar{X}=23,62 \pm 5,53$ ) ölçeklerinden aldıkları ortalama puanlar düşüktür. Öğrencilerin sanal zorba olma durumları ile cinsiyet, akademik başarı, internet kullanım süresi ve yaşanılan yer değişkenlerine göre anlamlı bir fark bulunmamıştır ( $p>0,05$ ). Öğrencilerin sanal kurban olma durumu ile interneti uzun süre kullanımları arasında anlamlı bir fark olduğu bulunmuştur $(p<0,05)$. Öğrencilerin sanal zorbalık esnasında en çok eğlenme $(\% 61,6)$, sanal kurban olan öğrencilerin kızgınlık $(\% 23,4)$, endişe $(\% 17,5)$ ve stres $(\% 15,4)$ duyguları hissettikleri belirlenmiştir.

Sonuç: Çalışmada öğrencilerin sanal zorba ve sanal kurban ölçeklerinden almış oldukları puanların düşük olduğu bulunmuştur. Sanal kurban olan öğrencilerin uzun süreli internet kullanımları arasında anlamlı fark olduğundan güvenli internet kullanımına ilişkin eğitimlerin düzenlenmesi önemlidir.

\section{Abstract}

Aim: The development of technology not only increases interaction among university students and supports learning, but also brings some negative situations. One of these situations is the concept of

Künye: Sezer B, Demirören M. Tıp Fakültesi Öğrencilerinin Sanal Zorba ve Sanal Kurban Olma

Durumlarının Incelenmesi Tip Egitimi Dunyasi. 2021;20(61):106-118 
cyberbullying. In this study, it was aimed to determine the level of being a cyberbully/victim of first-year medical students at Hacettepe University.

Methods: The research was conducted according to survey model. The study group consisted of 307 students. Research data was obtained electronically via Personal Information Form and Cyberbullying/Cyber Victimization Scales. The data was analyzed with SPSS 22.0 statistical package program. Descriptive statistics were presented as number, percentages, mean and standart deviation. Mann Whitney $U$ and Kruskal Wallis analyzes, which are nonparametric tests, were performed for the analysis of the data.

Results: The average scores recorded by the students in the cyberbullying $(\bar{X}=21,04 \pm 3,64)$ and cyber victimization ( $\bar{X}=23,62 \pm 5,53$ ) scales were low. There was no significant difference between level of being cyberbully of the students and gender, academic success, internet usage time and place of residence variables $(p>0,05)$. There was a significant difference between level of being cybervictim of the students and the use of internet for a long time $(p<0,05)$. It was determined that cyberbullied students experienced feelings of fun $(\% 23,4)$, and the cybervictims experienced feelings of anger $(\% 23,4)$, anxiety $(\% 17,5)$ and stress $(\% 15,4)$.

Conclusions: In this study, the scores of students' in the cyberbullying and cyber victimization scales were found low. Since there was a significant difference between cybervictimization and students' long-time internet usage, it is important to organize trainings on safe internet use.

\section{GíRIŞ}

Üniversite öğrencileri interneti iletişim amaçlı olduğu kadar, eğitsel amaçlı görevleri yerine getirmek içinde yoğun biçimde kullanmaktadırlar (1). Bu internet teknolojileri öğrenciler arasında etkileşimi artırması, öğrenmenin desteklenmesi gibi katkılarının yanında, bazı olumsuz durumları da beraberinde getirmektedir. Bu durumlardan biri de sanal zorbalık (cyberbullying) kavramıdır. Sanal zorbalık, cep telefonu, e-posta, web siteleri vb. bilişim teknolojileri aracılığı ile bireyin bir diğer bireye/bireylere tehdit, taciz, korkutma vb. kötü amaçlı, sürekli, kasıtlı davranışlar sergilemesi olarak tanımlanmaktadır $(2,3)$. Bu teknolojilerin kötüye kullanılması sonucu ortaya çıkan sanal zorbalığı güçlendiren ve yayılmasını kolaylaştıran en önemli nedenler; kişinin fiziksel güce ihtiyaç duymaması, yer/zaman sınırlamasının olmamas1, zorbanın gizlenebilmesi, kurbana kolay ulaşılabilir olması ve kurbanı kolay bir şekilde baskı altına almasidir (2).

Sanal zorbalık içeren eylemlerde bulunan bireylere sanal zorba, bu eylemlere maruz kalanlara ise sanal kurban denilmektedir (4). Yapılan çalışmalar, sanal zorba olma ya da kurban olmanın birey üzerinde düşük özsayg1, Tıp Eğitimi Dünyası / Mayıs-Ağustos 2021 / Say1 61 depresyon, endişe, motivasyon eksikliği, akademik başarısızlık, derslerde devamsızlık yapma, paranoya, korku ve üzüntü gibi çeşitli olumsuz psikososyal etkilerinin olduğunu göstermektedir $(5,6)$. Üniversitelerine yeni başlayan öğrenci yaş grubu hem zorbalı̆̆ daha sıklıkla uygulamakta hem de zorbalığa maruz kalabilmektedir (7). Üniversite öğrencilerinin diğer yaş grupları ve dönemlere göre böyle bir durumla karşılaştıklarında daha çok depresif davrandıkları, anksiyetelerinin daha yoğun olduğu ve paranoya düzeyinde yaşam sürdükleri $(8,9)$, akademik başarılarının hızla düştüğü $(10)$, kişilerarası iletişim ve ilişkilerde güçlük yaşadıkları (10), intihara teşebbüs ettikleri (9) belirlenmiştir. Araştırmalarda sanal zorbaların, görece azınlık durumdaki etnik köken/1rka sahip bireylere, engellilik (davranışsal, duyuşsal, fiziksel) durumu olanlara ve yalnız yaşayan bireylere yöneldikleri de görülmektedir (11).

Özellikle üniversite öğrencilerinin çoğunun ailesinden uzakta olmasından kaynaklı internet kullanımına ilişkin daha denetimsiz olmaları, akademik ortamlarda sanal ortamdaki davranışları ile ilgili yeterli bilgilendirme ve rehberlik yapılmıyor olması da kendilerini daha fazla risk altında bırakmaktadır (12). Bununla 
birlikte sanal zorbalık, normal günlük zorbalık türünden daha hızlı biçimde yayılmakta ve bireyler bu durumun farkına varamamaktadırlar (11). Sanal zorbalık ile ilgili bazı araştırmalarda genellikle sanal zorbalık durumlarının lise düzeyinde görüldüğü bildirilse de gerçekleştirilen birçok araştırmada bu durumun üniversite düzeyinde de hızla devam ettiği, çoğunlukla ailesinden ayrı okumak zorunda kalan öğrencilerin daha çok risk altında olduğu bildirilmektedir (10,11). Birçok durumda cinsel içerikli mesajlaşma ile başlayan genç yetişkinler arasındaki iletişim, zamanla sanal zorbalığa dönüşmektedir (13). Gerçekleştirilen bir sistematik derleme çalışmasında üniversite öğrencileri arasında bu tür mesajlaşma oranının \%7-27 arasında olduğu, bu durumun olumsuz sonucunun sanal kurbanların intiharına kadar uzanabildiği belirlenmiştir (14). Diğer açıdan üniversite ortamlarında öğrenciler tarafından öğretim elemanlarına da sanal zorbalık yapıldığı görülmektedir. Örneğin Kanada'da dört farklı üniversitede görev yapan 331 öğretim elemanı ile gerçekleştirilen bir araştırmada özellikle kadın öğretim elemanlarının öğrenciler tarafindan sanal kurban edildikleri belirlenmiştir (10). Aynı araştırmada 1925 öğrencinin de sanal kurban oldukları bulunmuştur (10).

Zorbalığın elektronik ortamda yapılan bir türü olarakta düşünülebilen sanal zorbalık kavramı üzerinde yapılan çoğu çalışmanın üniversite öğrencileri yerine daha ön dönemlerde (ilkokul, ortaokul, lise) yapıldığı görülse de son zamanlarda sanal zorbalığın üniversite düzeyinde de hızla devam ettiği ortaya koyulmuştur (15-19). Örneğin Sam ve ark. (19) yaptıkları araştırmada üniversitede öğrenim gören öğrencilerin lise düzeyine göre daha s1k sanal zorbalığa maruz kaldıklarını belirlemişlerdir. Souza ve ark. (18) araştırmalarında üniversiteye yeni başlayan öğrencilerde hem psikolojik nedenler hem de kampüs ikliminden (üst sınıf zorbalığı vb.) kaynaklanan sanal zorbalık vakalarının olduğu belirlenmiştir. $\mathrm{Bu}$ konuda üniversiteye yeni başlayan öğrencilere yönelik hem kurban hem zorbalık eğitimlerinin verilmesi ve yeni çalışmalarla literatürün zenginleşmesi önerilmektedir (18). Bu bağlamda, bu çalışmada fakültelerinde birinci sınıfta öğrenim gören tıp fakültesi öğrencilerinin sanal zorba/kurban olma düzeyleri ve bu durumlarda ne hissettiklerinin belirlenmesi amaçlanmıştır. $\mathrm{Bu}$ amaç doğrultusunda öğrencilerin sanal zorba/kurban olma düzeyleri cinsiyet, akademik başarı, günlük internet kullanım süresi, yaşanılan yer değişkenlerine göre fark göstermekte midir? sorusuna da yanıt aranmıştır.

\section{GEREÇ VE YÖNTEM}

Araştırma tarama modeline göre gerçekleştirilmiştir. Hacettepe Üniversitesi Etik Komisyonundan çalışma için etik onay (Tarih: 11.02.2019, Sayı: 35853172-900) alınmıştır.

\section{Katılımcilar}

Araştırmanın evrenini Hacettepe Üniversitesi Tıp Fakültesi 2018-2019 eğitim-öğretim yılında Dönem 1'de öğrenim gören 436 öğrenci oluşturmuştur. Öğrencilerin tümüne ulaşılması hedeflendiğinden ayrıca bir örneklem oluşturulmamıştır. Veri toplama araçları Google Form ile elektronik hale dönüştürülmüş, amfi dersleri öncesinde öğrencilere gerekli açıklamalar yapılarak katılım linkleri kendileri ile paylaşılmıştır. Çalışmaya katılım gönüllülük esasına dayanmıştır. Veri toplama esnasında derse katılım göstermeyen ya da çalışmaya katılmak istemeyen öğrenciler bulunduğundan 307 öğrenci (tüm öğrenci grubunun \%74'ü) bu araştırmanın çalışma grubunu oluşturmuştur.

\section{Veri Toplama Araçlart}

Araştırmada veri toplama formu iki bölümden oluşmaktadır. İlk bölümde demografik veriler için Kişisel Bilgi Formu, ikinci bölümde ise sanal zorba ve sanal kurban olma durumlarının belirlenebilmesi için Sanal Zorba/Kurban Ölçeği yer almıştır. Kullanılan veri toplama araçlarına ait bilgilere aşağıda yer verilmiştir. 


\section{Kişisel Bilgi Formu}

Öğrencilerin yaş, cinsiyet, internet kullanım sıklığı, akademik başarı not ortalaması vb. temel bilgilerini elde etmek için araştırmacilar tarafindan geliştirilmiştir. Akademik başarı not ortalaması araştırma verilerinin toplandığı ana kadarki komite notlarının ortalamalarının öğrenciler tarafından bildirilmesi ile hesaplanmıştır. 40-59 aralığı 'Düşük', 60-79 aralığ1 'Orta', 80-100 aralığ1 ise 'Yüksek' olarak değerlendirilmiştir.

\section{Sanal Zorbalık Ölçeği}

Ayas ve Horzum (20) tarafindan geliştirilen ölçeğin sanal zorba kısmında; lisede öğrenim gören öğrencilerin sanal zorbalık davranışlarını ne ölçüde yaptıkları, sanal kurban olma kısmında; sanal zorbalık eylemlerine ne sıklıkla maruz kaldıklarına ilişkin verilerin toplanması amaçlanmaktadır. İlk olarak 32 madde ile gerçekleştirilen ölçeğin yapı geçerliliği çalışmalarının ardından 19 madde ve üç faktörlü bir yapı elde edilmiştir. Alt boyutlar; 'sanal ortamda cinsel zorbalık', 'sanal ortamda engelleme ve zarar verme', 'sanal ortamda söylenti çıkarma' olarak adlandırılmıştır. Ölçekte yer alan maddelerin faktör yük değerleri 0,35-0,85 arasında değişmekte ve toplam varyansın \%44'ünü açıklamaktadır. Gerçekleştirilen doğrulayıcı faktör analizi sonucunda, ölçeğin uyum indeksleri $(\chi 2=$ $459,39$ ( $\mathrm{sd}=149, \mathrm{p}=0,000), \chi 2 / \mathrm{sd}=3,08$ $\mathrm{RMSEA}=0,068, \mathrm{GFI}=0,90, \mathrm{AGFI}=0,88, \mathrm{CFI}=$ $0,93, \mathrm{NFI}=0,90$ ve $\mathrm{NNFI}=0,92$ ) incelendiğinde uyum indekslerinin kabul edilebilir düzeyde olduğu görülmektedir. $\mathrm{Bu}$ analizler sonucunda ölçeğin yapı geçerliliğinin sağlandığ 1 belirtilmiştir. Güvenirlik çalışması için iç tutarlılık yöntemi (Cronbach-alpha katsayısı) kullanılmış olup, sanal zorba ölçeği için; Sanal Ortamda Cinsel Zorbalık alt faktörü için güvenirlik katsayısı 0,68, Sanal Ortamda Engelleme ve Zarar Verme alt faktörü için güvenirlik katsayısı 0,75, Sanal Ortamda Söylenti Çıkarma alt faktörü için güvenirlik katsayısı 0,68 olarak bulunmuştur. Sanal kurban ölçeği için ise; Sanal Ortamda Cinsel Zorbalık alt faktörü için güvenirlik katsayısı 0,66, Sanal Ortamda Engelleme ve Zarar Verme alt faktörü için güvenirlik katsayısı 0,62, Sanal Ortamda Söylenti Çıkarma alt faktörü için güvenirlik katsayısı 0,70 olarak bulunmuştur. Ölçekte yer alan maddelerle ilgili katılma düzeyini ifade etmek için 5'li Likert tipi dereceleme ([5]-Her zaman, [1]-Hiçbir zaman) kullanılmıştır. Alınabilecek en düşük puan 19, en yüksek puan ise 95'tir. Alınan puan arttıkça sanal zorbalık/kurbanlık düzeyide artmaktadır. Ölçeğin, üniversite öğrencilerinin katılımcı olarak yer aldığı bir çalışmada elde edilen iç tutarlılık güvenirlik katsayısı zorbalığa maruz kalma bölümü için 0,73 , zorbalı yapma bölümü için 0,74 olarak bulunmuştur (21). Bu çalışmada da ölçeğe ilişkin iç tutarlık güvenirlik katsayısına bakılmış olup, sanal zorba ölçeği için; Sanal Ortamda Cinsel Zorbalık alt faktörü için güvenirlik katsayısı 0,82, Sanal Ortamda Engelleme ve Zarar Verme alt faktörü için güvenirlik katsayısı 0,81, Sanal Ortamda Söylenti Çıkarma alt faktörü için güvenirlik katsayısı 0,78 olarak bulunmuştur. Sanal kurban ölçeği için ise; Sanal Ortamda Cinsel Zorbalık alt faktörü için güvenirlik katsayısı 0,86, Sanal Ortamda Engelleme ve Zarar Verme alt faktörü için güvenirlik katsayısı 0,82, Sanal Ortamda Söylenti Çıkarma alt faktörü için güvenirlik katsayısı 0,80 olarak bulunmuştur.

\section{Verilerin Toplanmast ve Analizi}

Veriler elektronik olarak Google Form aracılığı ile toplanmıştır. Veri toplama süreci yedi hafta (6 Mart 2019 - 24 Nisan 2019) sürmüştür. Her hafta gerçekleştirilen mesleksel beceri eğitimleri (bu oturumlara her hafta yaklaşık 6070 öğrenci katılmakta) öncesinde araştırmacılar tarafindan sözel bilgilendirme yapılarak veriler toplanmıştır. $\mathrm{Bu}$ bilgilendirmelerde; sanal zorba/kurban olma tanımları, hangi durumların bu siniflamaya dahil edilebileceği, bu durumlarda neler yapılabileceği, verilerin doğru biçimde girilmesinin önemi, gönüllülük esasına göre katılım sağlanabileceği vb. gibi bilgiler 
verilmiştir. Verilerin analizi Statistical Package for the Social Sciences (SPSS) 22.0 istatistik programı ile yapılmıştır. Tanımlayıcı istatistikler say1, yüzde, ortalama ve standart sapma olarak sunulmuştur. Veri setinin homojenliğini test etmede Levene istatistiği, normallik varsayımının sinanmasında ise Shapiro-Wilks testinden faydalanılmıștır. Ölçeklerden elde edilen verilerin normal dağılmadığı ve varyansların homojen dağılım göstermediği belirlendiğinden parametrik olmayan testlerden Mann Whitney $U$ ve Kruskal Wallis testleri kullanılmıştır. Verilerin karşılaştırılmasında istatistiksel anlamlılık düzeyi .05 olarak kabul edilmiştir. Ölçeklerden elde edilen toplam ve alt boyut puanları arasında karşılaştırma yapabilmek için puanlar 100'e dönüştürülerek ifade edilmiştir.

\section{BULGULAR}

\section{Katılımcılara İlişkin Bilgiler}

Araştırmada katılan 307 öğrenciye (tüm öğrenci sayısının \%74'ü) ilişkin demografik bilgilere ilişkin bilgiler Tablo 1'de sunulmuştur.

Tablo 1. Katılımcılara İlişkin Bilgiler

\begin{tabular}{|c|c|c|c|}
\hline Değişken & Seçenekler & $\mathbf{n}$ & $\%$ \\
\hline \multirow[b]{2}{*}{ Cinsiyet } & Kadın & 138 & 44,8 \\
\hline & Erkek & 169 & 55,2 \\
\hline \multirow{3}{*}{ Akademik Not Ort. } & $40-59$ & 37 & 12,3 \\
\hline & $60-79$ & 147 & 47,8 \\
\hline & $80-100$ & 123 & 39,9 \\
\hline \multirow{5}{*}{ Günlük internet kullanım süresi } & $0-1$ saat & 73 & 23,7 \\
\hline & $2-3$ saat & 60 & 19,8 \\
\hline & 4-5 saat & 92 & 29,9 \\
\hline & 6-7 saat & 46 & 14,9 \\
\hline & 7 ve daha fazla & 36 & 11,7 \\
\hline \multirow{4}{*}{ Yaşanılan yer } & Ev (aile ile) & 102 & 33,4 \\
\hline & Ev (arkadaşlar ile) & 10 & 3,2 \\
\hline & Ev (yalnız) & 10 & 3,2 \\
\hline & Yurt & 185 & 60,2 \\
\hline \multirow{2}{*}{$\begin{array}{l}\text { Daha önce sanal zorbalık kavramını duymuş } \\
\text { muydunuz? }\end{array}$} & Evet & 240 & 78,2 \\
\hline & Hayır & 67 & 21,8 \\
\hline \multirow{4}{*}{ Son 3 ayda sanal zorbalığa uğradınız mı? } & Hayır uğramadım & 252 & 82,1 \\
\hline & 1-2 Kere & 41 & 13,4 \\
\hline & 3-4 Kere & 5 & 1,6 \\
\hline & Çok Kez & 9 & 2,9 \\
\hline \multirow{4}{*}{ Son 3 ayda sanal zorbalık uyguladınız mı? } & Hayır uygulamadım & 277 & 90,2 \\
\hline & $1-2$ Kere & 19 & 6,2 \\
\hline & 3-4 Kere & 4 & 1,3 \\
\hline & Çok Kez & 7 & 2,3 \\
\hline \multirow{2}{*}{$\begin{array}{l}\text { Sanal zorbalık olaylarına müdahale konusunda } \\
\text { kendinizi yeterli hissediyor musunuz? }\end{array}$} & Evet & 76 & 24,9 \\
\hline & Hayır & 231 & 75,1 \\
\hline \multirow{2}{*}{$\begin{array}{l}\text { Sanal zorbalık konusunda eğitime ihtiyacınız } \\
\text { olduğunu düşünüyor musunuz? }\end{array}$} & Evet & 195 & 63,6 \\
\hline & Hayır & 112 & 36,4 \\
\hline
\end{tabular}

\section{Öğrencilerin Sanal Kurban / Sanal Zorba Olma Düzeyleri}

Öğrencilerin sanal zorba ve sanal kurban olma düzeylerine ilişkin öğrencilerden elde edilen veriler Tablo 2'de sunulmuştur. 
Tablo 2. Öğrencilerin Sanal Zorba/Kurban Ölçeğinden Elde Edilen Puanları ( $b=307)$

\begin{tabular}{|c|c|c|c|c|}
\hline \multirow{2}{*}{$\begin{array}{l}\text { Sanal } \\
\text { Zorba/Kurban } \\
\text { Ölçeği }\end{array}$} & \multicolumn{2}{|c|}{ Sanal Kurban Olma Puanları } & \multicolumn{2}{|c|}{ Sanal Zorba Olma Puanları } \\
\hline & Ort \pm ss & Min-Maks & Ort \pm ss & Min-Maks \\
\hline Cinsel zorbalık & $8,7 \pm 2,31$ & $7-21$ & $7,73 \pm 1,67$ & $7-21$ \\
\hline $\begin{array}{l}\text { Engelleme ve zarar } \\
\text { verme }\end{array}$ & $9,67 \pm 2,22$ & $8-24$ & $8,65 \pm 1,4$ & $8-20$ \\
\hline Söylenti çıkarma & $5,25 \pm 1,98$ & $4-15$ & $4,65 \pm 1,33$ & $4-13$ \\
\hline Toplam puan & $23,62 \pm 5,53$ & $19-47$ & $21,04 \pm 3,64$ & $19-48$ \\
\hline
\end{tabular}

Çeşitli Değişkenlere Göre Öğrencilerin Sanal Zorba Olma Durumlart

Araştırmanın 'Öğrencilerin sanal zorba olma düzeyleri cinsiyet, akademik başarı, günlük internet kullanım süresi, yaşanılan yer değişkenlerine göre fark göstermekte midir?' alt problemine yanıt bulmak için hem ilgili değişkenlere ilişkin betimsel istatistikler verilmiş hem de Mann Whitney U ve Kruskal Wallis testleri uygulanmıştır. Sonuçlar Tablo 3 'te sunulmuştur.

Tablo 3'te görüldüğg̈ üzere, gerçekleştirilen analiz sonucunda ögrencilerin sanal zorba olma puanları cinsiyet, akademik başarı, günlük internet kullanım süresi ve yaşanılan yer değişkenlerine göre istatistiksel olarak anlamlı farkl1lık göstermemektedir.

\section{Öğrencilerin Sanal Kurban Olma Durumlarının Çeşitli Değişkenlere Göre Farklılaşma Durumu}

Araştırmanın 'Öğrencilerin sanal kurban olma düzeyleri cinsiyet, akademik başarı, günlük internet kullanım süresi, yaşanılan yer değişkenlerine göre fark göstermekte midir?' alt problemine yanıt bulmak için hem ilgili değişkenlere ilişkin betimsel istatistikler verilmiş hem de Mann Whitney U ve Kruskal Wallis testleri uygulanmıştır. Sonuçlar Tablo 4 'te verilmiştir.

Öğrencilerin sanal kurban olma ölçeğinden aldıkları puanların cinsiyete ve akademik başarılarına göre tüm alt boyutlarda farklılaşmadığı görülmektedir. Öğrencilerin sanal kurban olma puanlarının tüm alt boyutlarda internet kullanım süresine göre farklılaştı $\breve{g}_{1}$ görülmektedir $(\mathrm{KW}=12,095$, $\mathrm{p}=0,017)$. Farkın kaynağının günlük internet kullanım süresinin artması ile doğru orantılı olduğu belirlenmiştir. Öğrencilerin sanal kurban olma puanlarının yaşanılan yer değişkenine göre yalnızca 'Engellenme/zarar verme' at boyutunda farklılaştığı $(\mathrm{KW}=9,729$, $\mathrm{p}=0,021$ ), diğer alt boyutlarda ve toplam puanlarında farklılaşmadığı görülmektedir (toplam puan $\mathrm{KW}=5,624, \quad \mathrm{p}=0,131$ ). 'Engellenme/zarar verme' alt boyutunda farkın kaynağının; 'Evde ailesiyle birlikte yaşayan öğrenciler' ile 'Evde arkadaşlarıyla yaşayan öğrenciler’ arasında olduğu belirlenmiştir $(\mathrm{p}=0,037)$. 
Tablo 3. Öğrencilerin Sanal Zorba Olma Düzeylerinin Çeşitli Değişkenlere Göre Fark Göstermesine İlişkin Analiz Sonuçları

\begin{tabular}{cccc}
$\begin{array}{c}\text { Cinsel } \\
\text { Zorbalık }\end{array}$ & $\begin{array}{c}\text { Engelleme/Zarar } \\
\text { Verme }\end{array}$ & $\begin{array}{c}\text { Söylenti } \\
\text { Çıkarma }\end{array}$ & $\begin{array}{c}\text { Toplam } \\
\text { Puan }\end{array}$ \\
\hline Sıra Ort. & Sıra Ort. & Sıra Ort. & Sıra Ort.
\end{tabular}

\section{Cinsiyet}

\begin{tabular}{|c|c|c|c|c|}
\hline $\operatorname{Kadin}(n=138)$ & 135,5 & 135,1 & 141,1 & 129,1 \\
\hline Erkek $(\mathrm{n}=169)$ & 169,1 & 169,4 & 164,5 & 174,4 \\
\hline MWU & 6387,500 & 5906,000 & 6178,5 & 5993,5 \\
\hline $\mathbf{p}$ & 0,605 & 0,092 & 0,318 & 0,203 \\
\hline \multicolumn{5}{|l|}{ Akademik Başarı } \\
\hline Düşük (n=37) & 139,2 & 168,4 & 156,6 & 157,6 \\
\hline Orta $(n=147)$ & 157,5 & 156,6 & 156,8 & 156,5 \\
\hline Yüksek (n=123) & 154,7 & 146,5 & 149,8 & 149,8 \\
\hline KW & 1,783 & 3,09 & 0,665 & 0,0519 \\
\hline $\mathbf{p}$ & 0,410 & 0,213 & 0,717 & 0,771 \\
\hline \multicolumn{5}{|c|}{ İnternet Kullanım Süresi } \\
\hline $0-1$ saat $(n=73)$ & 148,9 & 149,1 & 161,5 & 154,2 \\
\hline $2-3$ saat $(n=60)$ & 144,3 & 157,8 & 143,9 & 142,1 \\
\hline $4-5$ saat $(n=92)$ & 152,5 & 147,2 & 143,7 & 147,7 \\
\hline $6-7$ saat $(n=46)$ & 161,7 & 145,7 & 164,9 & 159,9 \\
\hline 7 ve üstü saat(n=36) & 174,2 & 185,4 & 167,5 & 181,5 \\
\hline KW & 4,724 & 9,076 & 6,087 & 5,864 \\
\hline $\mathbf{p}$ & 0,317 & 0,069 & 0,165 & 0,210 \\
\hline \multicolumn{5}{|l|}{ Yaşanılan Yer } \\
\hline Ev (aile ile) $(n=102)$ & 153,3 & 157,3 & 149,5 & 152,7 \\
\hline Ev (arkadaş ile) $(n=10)$ & 180,7 & 163,7 & 168,7 & 181,6 \\
\hline Ev (yalnız) $(n=10)$ & 138,2 & 161,3 & 139,1 & 159,6 \\
\hline Yurt $(n=185)$ & 153,7 & 151,2 & 156,4 & 152,8 \\
\hline KW & 1,824 & 0,802 & 1,426 & 1,193 \\
\hline $\mathbf{p}$ & 0,610 & 0,849 & 0,700 & 0,755 \\
\hline
\end{tabular}


Tablo 4. Öğrencilerin Sanal Kurban Olma Durumlarının Çeşitli Değişkenlere Göre Farklılaşmasına İlişkin Analiz Sonuçları

\begin{tabular}{|c|c|c|c|c|}
\hline & $\begin{array}{c}\text { Cinsel } \\
\text { Zorbalık }\end{array}$ & $\begin{array}{c}\text { Engelleme/Zarar } \\
\text { Verme }\end{array}$ & $\begin{array}{c}\text { Söylenti } \\
\text { Çıkarma }\end{array}$ & $\begin{array}{c}\text { Toplam } \\
\text { Puan }\end{array}$ \\
\hline & Sira Ort. & Sira Ort. & Sira Ort. & Sira Ort. \\
\hline \multicolumn{5}{|l|}{ Cinsiyet } \\
\hline $\operatorname{Kadin}(n=138)$ & 158,6 & 155,1 & 152,2 & 154,1 \\
\hline Erkek $(\mathrm{n}=169)$ & 150,2 & 153,1 & 155,4 & 153,9 \\
\hline MWU & 6542,500 & 5873,000 & 6083,000 & 5986,500 \\
\hline $\mathbf{p}$ & 0,904 & 0,134 & 0,266 & 0,219 \\
\hline \multicolumn{5}{|l|}{ Akademik Başarı } \\
\hline Düşük $(n=37)$ & 139,4 & 146,6 & 154,1 & 144,4 \\
\hline Orta $(n=147)$ & 159,1 & 156,3 & 156,1 & 158,1 \\
\hline Yüksek (n=123) & 152,2 & 153,4 & 151,5 & 152,1 \\
\hline KW & 1,689 & 0,392 & 0,211 & 0,796 \\
\hline $\mathbf{p}$ & 0,430 & 0,822 & 0,900 & 0,672 \\
\hline \multicolumn{5}{|l|}{ İnternet Kullanım Süresi } \\
\hline $0-1$ saat $(n=73)$ & 139,5 & 131,5 & 143,2 & 134,2 \\
\hline $2-3$ saat $(n=60)$ & 126,5 & 149,7 & 161,8 & 141,1 \\
\hline $4-5$ saat $(n=92)$ & 163,8 & 156,2 & 146,1 & 157,4 \\
\hline $6-7$ saat $(n=46)$ & 173,7 & 184,8 & 177,5 & 186,8 \\
\hline 7 ve üstü saat(n=36) & 178,7 & 161,3 & 152,7 & 164,8 \\
\hline KW & 15,240 & 11,582 & 6,497 & 12,095 \\
\hline $\mathbf{p}$ & 0,004 & 0,021 & 0,045 & 0,017 \\
\hline \multicolumn{5}{|l|}{ Yaşanılan Yer } \\
\hline Ev (aile ile) $(\mathrm{n}=102)$ & 145,4 & 152,9 & 152,8 & 149,3 \\
\hline Ev (arkadaş ile) $(n=10)$ & 179,6 & 236,4 & 204,4 & 215,2 \\
\hline $\operatorname{Ev}($ yalnız) $(n=10)$ & 185,1 & 148,3 & 136,4 & 172,3 \\
\hline Yurt (n=185) & 155,6 & 150,4 & 152,8 & 152,2 \\
\hline KW & 3,370 & 9,729 & 4,324 & 5,624 \\
\hline $\mathbf{p}$ & 0,338 & 0,021 & 0,229 & 0,131 \\
\hline
\end{tabular}


Tablo 5. Sanal Zorba Olan Öğrencilerin Duygu Durumları

\begin{tabular}{lcc}
\hline Duygu Durumu & n & \% \\
\hline Eğlenme & 29 & 61,6 \\
\hline Mutluluk & 12 & 25,6 \\
\hline İntikam & 6 & 12,8 \\
\hline
\end{tabular}

\section{Öğrencilerin Sanal Kurban Olma Esnasında Hissettikleri Duygular}

Sanal kurban olduğunu ifade eden öğrencilere 'sanal zorbalığa uğradığınızda ne hissettiniz?' diye sorulan soruda öğrenciler kendilerine bildirilen durumları birden fazla olarak seçebildiği gibi, kendileri de açık uçlu olarak ekleyebilmişlerdir. Öğrencilerin vermiş olduğu

yanıtlar aşağıdaki tabloda verilmiştir. Tablo 6 incelendiğinde öğrenciler sanal kurban olduklarında en çok kızgınlık ve daha sonra sırası ile endişe, stres ve utanma duygusu hissettiklerini ifade etmişlerdir.

Tablo 6. Sanal Kurban Olan Öğrencilerin Duygu Durumları

\begin{tabular}{lcc}
\hline Duygu Durumu & $\mathbf{n}$ & $\mathbf{\%}$ \\
\hline Kızgınlık & 44 & 23,4 \\
\hline Endişe & 33 & 17,5 \\
\hline Stres & 29 & 15,4 \\
\hline Utanma & 27 & 14,4 \\
\hline Üzgün & 24 & 12,8 \\
\hline Korku & 18 & 9,6 \\
\hline Depresyon & 13 & 6,9 \\
\hline
\end{tabular}

\section{TARTIŞMA}

Tıp fakültesi birinci sınıfta öğrenim gören ögrencilerin sanal zorba/kurban olma düzeyleri ve bu durumlarda ne hissettiklerinin belirlenmesi amacıyla yapılan bu çalışmada ögrencilerin \%17,9'unun sanal zorbalıkla karşılaştı̆ı ve $\% 9,8^{\prime}$ 'inin ise sanal zorbalık yaptıkları belirlenmiştir. Öğrencilerin yalnızca $\% 24,9$ 'u sanal zorbalıkla mücadele konusunda kendilerini yeterli görebildiklerini dile getirmişlerdir. Yine öğrencilerin \%63,6's1 sanal zorbalık ile mücadele konusunda eğitime ihtiyaçlarının olduğunu bildirmişlerdir. Araştırmada elde edilen öğrencilerin son üç ayda düşük düzeyde sanal zorba/kurban olma düzeyleri literatürle benzerlik göstermemektedir. Bayram ve Saylı (22), araştırmalarında üniversite öğrencilerinin \%30,6'sının sanal zorbalı̆̆a maruz kaldığını ortaya koymuştur. Bu durum Dilmaç'ın (23) çalışmasında $\% 22,5$, Walker ve arkadaşlarının (24) çalışmasında \%21 olarak elde edilmiştir. $\mathrm{Bu}$ benzer olmayan sonuçların nedenleri araştırmaların bağlamlarından ve kurumsal farklardan kaynaklanabilir. Araştırmada elde edilen düşük sanal zorba/kurban olma düzeyi Hacettepe Üniversitesi Tıp Fakültesi'nde son iki yıldır dönem 1 öğrencilerine Bilgi Okuryazarlı̆̆ adlı dört saatlik (iki saat kuramsal, iki saat bilgisayar laboratuvarında uygulamal1) program kapsamında (verilerin toplanmasından önce bu eğitim alınmıştır) güvenli internet kullanımı, veri güvenliği vb. konularda bilgilendirmelerin yapılmış olmasından kaynaklı olabilir. Daha kapsamlı ve planlı verilecek sanal zorbalık bilgilendirmelerinin/eğitimlerinin daha etkili olabileceği söylenebilir. 
Öğrencilerin sanal kurban olma ortalama puanları, sanal zorba olma puanlarından yüksek çıkmıştır. Benzer bir bulguya yurtiçinde Fırat ve Ayran (6) tarafından 1864 üniversite öğrencisi ile gerçekleştirilen çalışmada da ulaşılmıştır (21). Fırat ve Ayran'ın (6) çalışmasında da öğrencilerin sanal kurban puan ortalamaları, sanal zorba ortalamasından yüksek çıkmıştır. Henüz 2000'li yılların başında Pişkin (25) tarafindan yapılan araştırmada da öğrencilerin \%35'i kurban, \%6'sının zorba, \%30'unun ise hem zorba hem kurban olduğu belirlenmiştir. Veriler değerlendirildiğinde öğrencilerin cinsiyetleri açısından sanal zorba olma durumları arasında istatistiki bir farklılık bulunmamıştır. Bu sonuç çeşitli araştırmalarla $(26,27)$ tutarlılık göstermektedir. Öte yandan, yapılan araştırmaların bazılarında $(28,29)$ kadınların daha fazla sanal zorbalık yaptığı, bazılarında da $(23,30)$ erkeklerin daha fazla sanal zorbalık yaptığı tespit edilmiştir. Öğrencilerin internet kullanım sürelerinin arttıkça sanal kurban olma düzeylerinin de arttığı belirlenmiştir. Öğrencilerin \%30'nun 4-5 saat, \%15'inin 6-7 saat, \%11,7'sinin 7 ve üstü saat internette aktif olarak yer aldıkları bildirilmiştir. Literatür öğrencilerin bu kadar uzun süre internette aktif yer almalarını problemli bulmakta (31), bu durumun başta fiziksel olmak üzere, akademik, ve sosyal açıdan olumsuz taraflarına dikkat çekmektedir (31). Öğrencilerin bu kadar uzun sürelerini internette geçiriyor olmaları ve büyük çoğunluğunun sosyal ağlara dahil olmaları bu konuda düzenlenecek eğitimlerin sosyal ağlarda güvenlik konularının başta olmak üzere, akıllı internet kullanımı, sanal aylaklık vb. konuları içermesi gerektiği önerilebilir.

Araştırmada öğrenciler sanal zorbalık uyguladığında en çok eğlenme, daha sonra sırası ile mutluluk ve intikam duygusu hissettiklerini bildirmişlerdir. Öğrencilerin sanal kurban olma durumlarının (engellenme/zarar verme alt boyutunda) yaşanılan yere göre 'evde arkadaşlarıyla yaşayan öğrenciler' ile 'evde ailesiyle yaşayan öğrenciler' arasında fark göstermesi, bu farkın kaynağının arkadaşlarıyla yaşayan öğrenciler aleyhine olması, bu sanal zorbalık eylemlerinin aynı ortamı paylaşan öğrenciler arasında gerçekleşip gerçekleştirilmediği araştırılabilir. $\mathrm{Bu}$ durum özellikle nitel araştırmalarla çalışılmalıdır. Eğlenme durumu, hem sanal zorba hem sanal kurban olma ile ilişkili ve sorunlu bir durumdur. Parris ve ark. (32), ergenlerin kullandıkları sanal zorbalıkla başa çıkma yöntemlerinin ne olduğunun belirlenmesi amaciyla yapılan çalışmada, sanal kurbanlar (a) reaktif başa çıkma (yapılanı şakaya alma, kabul etme, destek arama), (b) önleyici başa çıkma (birine durumu aktarma, sosyal desteğe başvurma) ve (c) başa çıkmanın imkânsız olduğuna inanma yani herhangi bir stratejinin işe yaramayacağını düşünmektedirler. İlerideki çalışmalar ya da olası düzenlenecek eğitimlerde sanal zorbalığı önleme ya da sanal kurbanlara destek olmak için reaktif başa çıkma stratejilerinden biri olan 'şaka yapma' (aynı zamanda bu araştırmada da öğrenciler en çok eğlence olsun diye zorbalık yaptıklarını dile getirmişlerdir) ile ilgili ayrıntılı bilgi verilmeli ve bu yönde önlemler alınmalıdır.

\section{SONUÇ}

Öğrencilerin sanal zorbalık yapma (100 üzerinden 21,04) ve sanal zorbalığa maruz kalma (100 üzerinden 23,62) durumları düşük düzeydedir. Öğrenciler sanal zorbalık uyguladığında eğlenme, mutluluk ve intikam duyguları hissettiklerini bildirmişlerdir. Öğrenciler sanal kurban olduklarında ise kızgınlık, endişe, stres, utanma, üzgün olma gibi duygular yaşadıklarını bildirmişlerdir.

Öğrencilerin sanal zorba olma puanları cinsiyet, akademik başarı, günlük internet kullanım süresi ve yaşanılan yer değişkenlerine göre istatistiksel olarak anlamlı farklılık göstermemektedir. Öğrencilerin sanal kurban olma puanları cinsiyet ve akademik başarı değişkenlerine göre farklılaşmadığı görülmektedir. Ancak, öğrencilerin sanal kurban olma puanlarının tüm alt boyutlarda 
internet kullanım süresine göre farklılaştığı belirlenmiştir. Farkın kaynağının daha uzun süre internet kullanan öğrenciler aleyhine olduğu belirlenmiştir. Öğrencilerin sanal kurban olma puanlarının yaşanılan yer değişkenine göre yalnızca 'Engellenme/zarar verme' alt boyutunda farklılaştığı (farkın kaynağının; 'Evde ailesiyle birlikte yaşayan öğrenciler' ile 'Evde arkadaşlarıyla yaşayan öğrenciler' arasında, arkadaşlarıyla yaşayan öğrenciler aleyhine) olduğu belirlenmiştir.

Üniversitelerine yeni başlayan öğrencilere uyum haftasında ya da ilk dönemde sanal zorbalık bilgilendirilmesi yapılabilir. Sanal zorbalığın tüm yönleri hakkında bilgilendirmeyi hedefleyen panel vb. etkinlikler düzenlenebilir ve aşağıdaki konulara yer verilebilir;

- Sanal zorbalığın tanımı

- Sanal zorbalığın etkileri ve hukuki sonuçları

- Sanal zorbalıktan korunma/baş etme yöntemleri

- Sosyal ağları ve bilişim araçlarını güvenli kullanma

- Sanal zorbalıkla karşılaşıldığında yapılması gerekenler

- Empati

- Bilişim etiği

Süreklilik gösteren bir mekanizma kurularak öğrencilerin istedikleri anda destek alabilmeleri sağlanabilir. Bu noktada rehberlik/danışmanlık merkezleri önemli rol oynayabilir. $\mathrm{Bu}$ mekanizmalarda akran desteği/rehberliğine yer verilebilir. Buna ilaveten öğrencilerdeki depresyon ve kaygı belirtileri danışmanları tarafindan dönem dönem izlenebilir, gereksinim duyan öğrencilerle odak grup/bireysel görüşmeler ile sorunlara erken müdahale edilebilir. Yine bu merkezler üzerinden web destekli çevrimiçi başvurular alınarak hızlıca müdahaleler gerçekleştirilebilir. Daha üst düzeyde önlemler alınması da akran zorbalığı üzerine caydırıcı olabilir. Üniversiteler yasal düzenlemeler yaparak tüm kurum (personel, öğrenci vb.) ile paylaşabilir. Öğrenci toplulukları öğrencilerde ve personelde farkındalığ 1 artırmak için çeşitli etkinlikler düzenleyerek hem bilgilendirme hem de olası müdahale yöntemlerini aktarabilir. Çeşitli kurum/kuruluşlardan yetkili kişiler bu etkinliklere davet edilerek bu etkinliklerin gücü artır1labilir.

\section{KAYNAKLAR}

1. Y1lmaz R, Sezer B, Yurdugül, H. Üniversite öğrencilerinin bilgi ve iletişim teknolojilerinden yararlanma durumları ve alışkanlıkları üzerine bir araştırma: mevcut durum ve geleceğe bakış. Ege Eğitim Teknolojileri Dergisi. 2018;2(1):118.

2. Smith PK, Mahdavi J, Carvalho M, Fisher S, Russell S, Tippett N. Cyberbullying: Its nature and impact in secondary school pupils. J Child Psychol Psychiatry. 2008;49(4):376-385.

3. Ayas T, Horzum MB. Öğretmenlerin sanal zorbalık algılarının çeşitli değişkenlere göre incelenmesi. J Edu Sci. 2011;3(2):619-640.

4. Hinduja S, Patchin JW. Bullying, cyberbullying, and suicide. Arch Suicide Res. 2010; 14:206-221.

5. Wright MF, Li Y. The association between cyber victimization and subsequent cyber aggression: The moderating effect of peer rejection. J Youth Adolesc. 2013;42(5):662674.

6. Bonanno RA, Hymel S. Cyberbullying and internalizing difficulties: above and beyond the impact of traditional forms of bullying. J Youth Adolesc. 2013;42(5):685-697.

7. Firat A, Ayran G. Üniversite öğrencileri arasında sanal zorbalık. TAF Prev Med. 2016;15(4):322-330. 
8. Arıcak OT. Üniversite öğrencilerindeki siber zorbalık davranışlarının bir yordayıcısı olarak psikiyatrik belirtiler. Eurasian J Educ Res. 2009; 34:167-184.

9. Schenk AM, Fremouw WJ. Prevalence, Psychological impact, and coping of cyberbully victims among college students. J Sch Violence. 2012;11(1):21-37.

10. Cassidy W, Faucher C, Jackson M. Adversity in university: Cyberbullying and its impacts on students, faculty and administrators. Int $\mathrm{J}$ Environ Res Public Health. 2017;14(8):888.

11. Katz-Wise SL, Hyde JS. Victimization experiences of lesbian, gay, and bisexual individuals: A meta-analysis. J Sex Res. 2012;49(2-3):142-167.

12. Altundağ Y, Ayas T. Lise rehber öğretmenlerine yönelik tüm okul yaklaşımına dayalı sanal zorba farkındalığı ve sanal zorbalıkla başa çıkma stratejilerini kazandırma programının etkililiği [Doktora Tezi]. Sakarya: Sakarya Üniversitesi;2018.

13. Agustina JR, Gómez-Durán EL. Sexting: Research criteria of a globalized social phenomenon. Arch Sex Behav. 2012;41(6):1325-1328.

14. Gámez-Guadix M, Almendros C, Borrajo E, Calvete E. Prevalence and association of sexting and online sexual victimization among Spanish adults. Sex Res Soc Policy. 2015;12(2):145154.

15. Aboujaoude E, Savage MW, Starcevic V, Salame WO. Cyberbullying: Review of an old problem gone viral. J Adolesc Health. 2015;57(1):10-18.

16. Baek J, Bullock LM. Cyberbullying: A Cross-cultural Perspective. Emo Behav Diff. 2014;19(2):226-38.

Tıp Eğitimi Dünyası / Mayıs-Ağustos 2021 / Say1 61
17. Barlett CP, Gentile DA Anderson CA, Suzuki K, Sakamoto A, Yamaoka A. Crosscultural differences in cyberbullying behavior a short-term longitudinal study. J Cross Cult Psychol. 2014;45(2):300-13.

18. Souza SB, Veiga Simão AM, Ferreira AI, Costa Ferreira P. University students' perceptions of campus climate, cyberbullying and cultural issues: Implications for theory and practice. High Educ Stud. 2018;43(11):20722087.

19. Sam DL, Bruce D, Agyemang CB, Amponsah B, Arkorful H. Cyberbullying victimization among high school and university students in Ghana, Deviant Behavior, 2018; DOI:https://doi.org/10.1080/01639625.2018.14 93369

20. Ayas T, Horzum MB. Sanal zorba/kurban ölçek geliştirme çalışması. Akademik Bakış Dergisi. 2010; 19:1-17.

21. F1rat M, Ayran G. Üniversite öğrencileri arasında sanal zorbalık. TAF Prevent Med Bullet. 2016;15(4):322-329.

22. Bayram N, Saylı M. Üniversite öğrencileri arasında siber zorbalık davranışı. İÜHFM. 2013;71(1):107-116.

23. Dilmaç B. Sanal zorbalığı yordayan psikolojik ihtiyaçlar: Lisans öğrencileri için bir ön çalışma. Kuram Uygul Eğit Bil. 2009;9(3):1291-1325.

24. Walker CM, Sockman BR, Koehn S. An exploratory study of cyberbullying with undergraduate university students. Tech Trends. 2011;55(2):31-38.

25. Pişkin M. Okul zorbalığı: Tanımı, türleri, ilişkili olduğu faktörler ve alınabilecek önlemler. Kuram Uygul Egit Bil. 2002;2(2):531-562. 
26. Myers CA, Cowie H. Bullying at university: The social and legal contexts of cyberbullying among university students. J Cross Cult Psychol. 2017;48(8):1172-1182.

27. Arıcak OT, Kınay H, Tanrıkulu T. Siber zorbalık ölçeği'nin ilk psikometrik bulguları. Hasan Ali Yücel Eğit Fak Derg. 2012;17(1):101-114.

28. Campfield DC. Cyber bullying and victimization: Psychosocial characteristics of bullies, victims, and bully/victims [Doctoral Dissertation].Montana: The University of Montana; 2008.

29. Keith S, Martin ME. Cyber-bullying: Creating a culture of respect in a cyber world. ReclChild and Youth. 2005;13(4):224-228.

30. Ayas T, Horzum MB. İlköğretim öğrencilerinin sanal zorba ve mağdur olma durumu. İlköğretim Online. 2012;11(2):369380 .

31. Ünver H, Koç Z. Siber zorbalık ile problemli internet kullanımı ve riskli internet davranışı arasındaki ilişkinin incelenmesi. Türk Eğt Bil D. 2017;15(2):117-140.

32. Parris L, Varjas K, Meyers J, Cutts H. High school students' perceptions of coping with cyberbullying. Youth Soc. 2012;44(2):284-306. 